\title{
In vitro studies evaluating the activity of imipenem in combination with relebactam against Pseudomonas aeruginosa
}

\author{
Katherine Young ${ }^{1 *} \mathbb{D}$, Ronald E. Painter ${ }^{1}$, Susan L. Raghoobar ${ }^{1}$, Nichelle N. Hairston ${ }^{1}$, Fred Racine',
}

Douglas Wisniewski ${ }^{1}$, Carl J. Balibarr ${ }^{1}$, Artjohn Villafania', Rumin Zhang ${ }^{1}$, Daniel F. Sahm², Timothy Blizzard ${ }^{1}$,

Nicholas Murgolo ${ }^{1}$, Milton L. Hammond ${ }^{1 \wedge}$ and Mary R. Motyl ${ }^{1}$

\begin{abstract}
Background: The prevalence of antibiotic resistance is increasing, and multidrug-resistant Pseudomonas aeruginosa has been identified as a serious threat to human health. The production of $\beta$-lactamase is a key mechanism contributing to imipenem resistance in $P$. aeruginosa. Relebactam is a novel $\beta$-lactamase inhibitor, active against class $\mathrm{A}$ and $\mathrm{C} \beta$-lactamases, that has been shown to restore imipenem susceptibility. In a series of studies, we assessed the interaction of relebactam with key mechanisms involved in carbapenem resistance in $P$. aeruginosa and to what extent relebactam might overcome imipenem non-susceptibility.

Results: Relebactam demonstrated no intrinsic antibacterial activity against $P$. aeruginosa, had no inoculum effect, and was not subject to efflux. Enzymology studies showed relebactam is a potent (overall inhibition constant: $27 \mathrm{nM}$ ), practically irreversible inhibitor of $P$. aeruginosa AmpC. Among $P$. aeruginosa clinical isolates from the SMART global surveillance program (2009, $n=993 ; 2011, n=1702 ; 2015, n=5953 ; 2016, n=6165)$, imipenem susceptibility rates were $68.4 \%$ in $2009,67.4 \%$ in $2011,70.4 \%$ in 2015 , and $67.3 \%$ in 2016 . With the addition of $4 \mu \mathrm{g} / \mathrm{mL}$

relebactam, imipenem susceptibility rates increased to $87.6,86.0,91.7$, and $89.8 \%$, respectively. When all imipenemnon-susceptible isolates were pooled, the addition of $4 \mu \mathrm{g} / \mathrm{mL}$ relebactam reduced the mode imipenem minimum inhibitory concentration (MIC) 8-fold (from $16 \mu \mathrm{g} / \mathrm{mL}$ to $2 \mu \mathrm{g} / \mathrm{mL}$ ) among all imipenem-non-susceptible isolates. Of 3747 imipenem-non-susceptible isolates that underwent molecular profiling, 1200 (32\%) remained non-susceptible to the combination imipenem/relebactam (IMI/REL); $42 \%$ of these encoded class B metallo- $\beta$-lactamases, $11 \%$ encoded a class A GES enzyme, and no class D enzymes were detected. No relationship was observed between alleles of the chromosomally-encoded P. aeruginosa AmpC and IMI/REL MIC.
\end{abstract}

Conclusions: IMI/REL exhibited potential in the treatment of carbapenem-resistant $P$. aeruginosa infections, with the exception of isolates encoding class B, some GES alleles, and class D carbapenemases.

Keywords: $\beta$-Lactamase inhibitor, Carbapenem-resistant, Carbapenemase, Multidrug-resistant, MK-7655, Imipenem/ relebactam, Non-susceptible, Antibiotic resistance

\footnotetext{
* Correspondence: katherine_young@merck.com

Deceased

'Merck \& Co., Inc., 2015 Galloping Hill Road MN-410, Kenilworth, NJ 07033,

USA

Full list of author information is available at the end of the article
}

(c) The Author(s). 2019 Open Access This article is distributed under the terms of the Creative Commons Attribution 4.0 International License (http://creativecommons.org/licenses/by/4.0/), which permits unrestricted use, distribution, and reproduction in any medium, provided you give appropriate credit to the original author(s) and the source, provide a link to the Creative Commons license, and indicate if changes were made. The Creative Commons Public Domain Dedication waiver (http://creativecommons.org/publicdomain/zero/1.0/) applies to the data made available in this article, unless otherwise stated. 


\section{Background}

Pseudomonas aeruginosa is a non-fermenting, aerobic, non-enteric, gram-negative bacterium. Ubiquitous in the environment and globally distributed, it is a leading cause of severe nosocomial infections, particularly in comorbid, immunocompromised, and critically ill patients [1-6]. Antibacterial resistance rates in $P$. aeruginosa are increasing worldwide but show considerable geographic variation [7-20]. Multidrug-resistant (MDR) and extensively drug-resistant (XDR) $P$. aeruginosa strains are becoming increasingly more prevalent and are associated with substantial morbidity and mortality [21, 22].

Carbapenem antibiotics have a very broad antibacterial spectrum and are considered treatments of last resort against increasingly difficult-to-treat drug-resistant pathogens, including $P$. aeruginosa $[23,24]$. Imipenem, coadministered with the dehydropeptidase- 1 inhibitor cilastatin, remains a mainstay for the empiric and targeted treatment of serious infections, and its use is supported by a wealth of clinical experience [25]. The rise of MDR bacterial pathogens has led to widespread and extensive use of carbapenems. Subsequently, the incidence of carbapenem resistance in $P$. aeruginosa is now increasing worldwide [26-28]. Recent data show about $20 \%$ of clinical isolates in the US are non-susceptible (NS) to meropenem, increasing to $65-78 \%$ among $\operatorname{MDR}$ isolates [29, 30]. Globally, imipenem resistance in $P$. aeruginosa ranges from 16 to $35 \%[8,16,31-35]$.

In $P$. aeruginosa, non-susceptibility to carbapenems is mediated by a number of resistance mechanisms, which often act synergistically. These mechanisms include reduced permeability of the cell envelope to antibacterial agents through intrinsic characteristics and porin loss/alterations, expression of multidrug efflux pumps, target site alterations, and expression of $\beta$-lactamase enzymes [36-42]. Outer membrane porin D (OprD) is the major mechanism by which imipenem transits the $P$. aeruginosa outer membrane in order to enter the periplasmic space and interact with its molecular target (ie, penicillinbinding proteins $[\mathrm{PBP}])$. The two most common imipenem resistance mechanisms in this pathogen are: (a) production of carbapenemases (ie, $\beta$-lactamases able to hydrolyze carbapenems) and/or (b) overexpression of AmpC $\beta$-lactamase or extended-spectrum $\beta$-lactamases in conjunction with decreased OprD permeability, thereby reducing imipenem's ability to reach PBP [41-44]. Given the clinical relevance of increasing carbapenem resistance in $P$. aeruginosa, new treatments to overcome this problem are urgently needed. One such approach is the restoration of carbapenem susceptibility using $\beta$-lactamase inhibitors (BLI).

A novel BLI currently under clinical development is relebactam (MK-7655), which has been shown to restore the in vitro antibacterial activity of imipenem in
imipenem-NS strains of gram-negative pathogens, including $P$. aeruginosa [45-47]. Relebactam is a non- $\beta$ lactam, small-molecule diazabicyclooctane (DABCO) BLI with activity against class A carbapenemases (such as Klebsiella pneumoniae carbapenemase [KPC]) and class $\mathrm{C}$ cephalosporinases (including AmpC that can be expressed constitutively from chromosomally-encoded genes) but is inactive against class D carbapenemases like OXA-40 [46-48]. In $P$. aeruginosa, relebactam can restore imipenem susceptibility in otherwise resistant isolates that lack OprD and have either inducible or derepressed AmpC production [45-47]. Recent surveillance studies have demonstrated that the addition of relebactam reduced imipenem minimum inhibitory concentration (MIC) values about 4-fold and increased imipenem susceptibility in all $P$. aeruginosa isolates, including those that were NS and from a lower respiratory tract source [34, 45]. Additional data are needed to elucidate the effects of relebactam against resistance mechanisms in $P$. aeruginosa and to characterize the extent to which relebactam can overcome imipenem non-susceptibility in clinical isolates of this pathogen.

To help answer these questions, we conducted a range of in vitro experiments to evaluate the activity of relebactam against $P$. aeruginosa, including the interaction of relebactam with key mechanisms involved in carbapenem resistance. We also compared the in vitro activities of relebactam plus imipenem versus imipenem alone in several large, world-wide collections of recent clinical $P$. aeruginosa isolates and evaluated the molecular profile of non-susceptibility to the combination.

\section{Results}

\section{Enzymology studies}

Results for inhibition kinetic parameters and turnover number are shown in Fig. 1. Relebactam exhibited potent, practically irreversible inhibitory activity to $P$. aeruginosa AmpC with good acylation efficiency; it readily bound to and was acylated by the enzyme. Relebactam also demonstrated long target engagement time and remained bound to the enzyme before slow deacylation and dissociation. Furthermore, the measured turnover number is near unity, approaching that of an irreversible inhibitor.

\section{Relebactam efflux}

The phenotype of the laboratory-derived OprD-deficient mutant strains MB6477 (wild-type efflux-proficient) and MB6476 (multiple efflux-deficient), which were isogenic except for deletion of multiple efflux pumps, was confirmed through antibiograms (Table 1). The MIC values to levofloxacin and chloramphenicol were greatly affected by efflux with a 512-fold and > 128-fold difference in $\mathrm{MIC}$, respectively, between the wild-type and multiple 


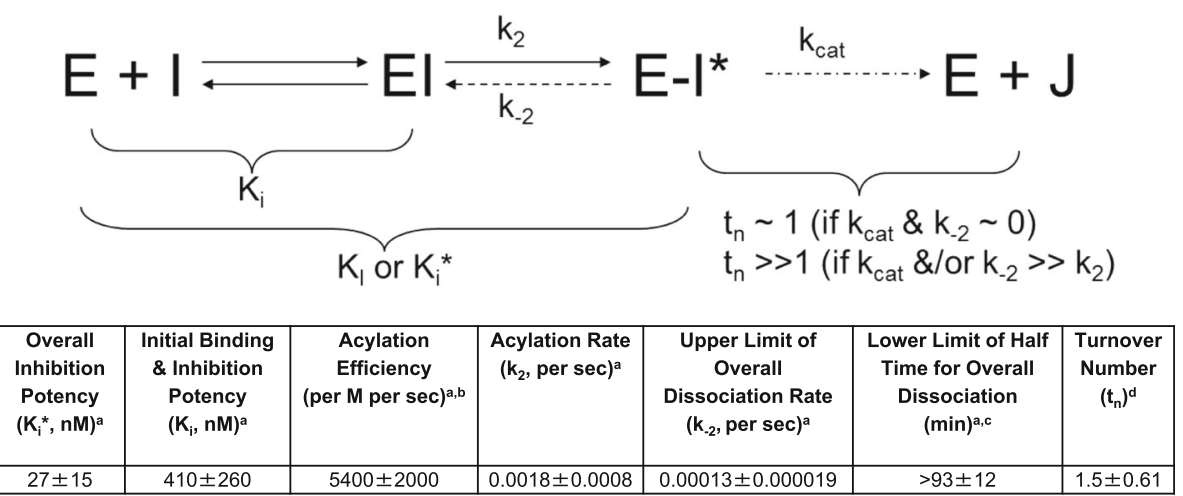

Fig. 1 Summary of enzymology studies: kinetic and mechanistic profiling for relebactam against P. aeruginosa AmpC. E: AmpC $\beta$-lactamase; El: noncovalent AmpC $\beta$-lactamase/relebactam complex; E-I*: acylated AmpC $\beta$-lactamase/relebactam complex; I: relebactam; J: hydrolyzed product; $k_{\text {cat: }}$ : turnover rate constant of $\beta$-lactamase inhibitor due to solvent water-mediated deacylation; $\mathrm{K}_{\mathrm{i}}$ : dissociation constant for the initial step of noncovalent binding; $\mathrm{K}_{\mathrm{i}}^{*}$ : overall dissociation constant for initial binding and subsequent acylation/deacylation step; $\mathrm{K}_{\mathrm{i}}$ inactivation constant (if $\mathrm{k}_{2} \sim 0$ ); $\mathrm{k}_{2}$ : acylation or inactivation rate constant; $\mathrm{k}_{-2}$ : intramolecular deacylation or recovery rate constant; $\mathrm{t}_{\mathrm{n}}$ : turnover number (number of compound turnover needed for complete inhibition); $\mathrm{k}_{2} / \mathrm{K}_{i}$ : acylation efficiency. Inhibition kinetic parameter data are based on results from 4 trials. ${ }^{b}$ Ratio of acylation rate constant $\left(k_{2}\right)$ over $K_{i}$, a measure of acylation efficiency. ${ }^{c} 0.693 / k_{-2}$, the minimum estimate of half time for overall inhibitor dissociation. ${ }^{d}$ Relebactam turnover number is based on data from 3 trials and with saturation time of $24 \mathrm{~h}$ (data for 2 -h saturation time not shown due to similarity with 24-h data)

efflux-deficient strains; aztreonam was less affected by efflux, with an 8 -fold difference in MIC. These results are expected, given that all of these control antibacterial agents are known resistance-nodulation-cell division (RND) efflux pump substrates $[49,51]$. The results of overexpression of each of the 4 RND efflux pumps of $P$. aeruginosa are shown in Table 1 ; the corresponding 4 mutant isolates were derived from MB6477. Of all antibacterial agents tested, meropenem was most affected by efflux pump overexpression, with a 16-fold increase in MIC in the strain overexpressing MexAB/OprM. The lack of increase in levofloxacin MIC in these pump overexpression mutants is likely due to masking by the underlying $n f x C$ mutation in the parental strain, which itself already confers decreased susceptibility to levofloxacin. No influence of efflux, either at baseline levels of RND efflux pump expression or upon overexpression, was seen for imipenem or imipenem/relebactam (IMI/REL), with identical MIC values across the isolate panel. The sole exception was the $\triangle n f x B$ isolate over-producing MexCD/Opr]; this mutation concurrently results in a down-regulation of $\mathrm{AmpC}$, which in turn results in lower $\beta$-lactam MIC values [52].

Table 1 Antibiogram of the OprD-deficient P. aeruginosa efflux mutant isogenic strain set showing MICs $(\mu \mathrm{g} / \mathrm{mL})^{a}$

\begin{tabular}{|c|c|c|c|c|c|c|c|}
\hline $\begin{array}{l}\text { Antibacterial } \\
\text { agent }\end{array}$ & $M B 6476^{b}$ & $M B 6477^{C}$ & $\begin{array}{l}\text { MIC } \\
\text { difference }^{d}\end{array}$ & $\begin{array}{l}\text { MB6477C } \Delta \text { mexR } \\
\text { (overexpresses MexAB) }\end{array}$ & $\begin{array}{l}\text { MB6477 } \Delta n f x B \\
\text { (overexpresses MexCD) }\end{array}$ & $\begin{array}{l}\text { MB6477` } \Delta \text { mexL } \\
\text { (overexpresses MexJK) }\end{array}$ & $\begin{array}{l}\text { MB6477 } \Delta \text { mexZ } \\
\text { (overexpresses } \\
\text { MexXY) }\end{array}$ \\
\hline Imipenem & 16 & 16 & 1-fold & 16 & 4 & 16 & 16 \\
\hline IMI/REL ${ }^{\mathrm{e}}$ & 1 & 1 & 1 -fold & 1 & 0.25 & 1 & 1 \\
\hline Ceftazidime $^{f}$ & 1 & 1 & 1-fold & ND & ND & ND & ND \\
\hline Aztreonam ${ }^{g}$ & 0.5 & 4 & 8-fold & ND & ND & ND & ND \\
\hline Meropenem ${ }^{f}$ & 1 & 1 to 2 & $\begin{array}{l}\text { 1- to 2- } \\
\text { fold }\end{array}$ & 16 & 4 & 2 & 2 \\
\hline Chloramphenicol $^{g}$ & 2 & $>256$ & $>128$-fold & ND & ND & ND & ND \\
\hline Levofloxacing & 0.0078 & 4 & 512-fold & 8 & 4 & 4 & 4 \\
\hline
\end{tabular}

IMI/REL imipenem/relebactam, MIC minimum inhibitory concentration, ND not determined, OprD outer membrane porin $\mathrm{D}$, RND resistance-nodulation-cell division ${ }^{\mathrm{a}} \mathrm{MIC}$ values were determined by 2 -fold serial broth microdilution

${ }^{\mathrm{b}} \mathrm{MB6476} n f x C, \Delta$ [MexAB-OprM] $\Delta$ [MexCD-OprJ] $\Delta$ [MexXY] $\Delta$ [MexJK-OprLL] $\Delta$ [MexHI-OpmD] $\Delta$ [OpmH]), spontaneous OprD deletion

${ }^{\mathrm{c}} \mathrm{MB6477} \mathrm{nfxC}$, wild-type for other efflux pumps, spontaneous OprD deletion

${ }^{d}$ Ratio between the MIC for MB6477 divided by the MIC for MB6476, for the respective antibacterial agent

Imipenem combined with $4 \mu \mathrm{g} / \mathrm{mL}$ of relebactam

${ }^{f}$ Control antibacterial agent known to be an RND efflux pump substrate, with susceptibility known to be adversely affected by efflux pump overexpression [49, 50] ${ }^{9}$ Control antibacterial agent known to be an RND efflux pump substrate, with susceptibility known to be adversely affected even in wild-type $P$. aeruginosa with baseline efflux pump expression $[49,50]$ 
Table 2 BLI concentration required to restore imipenem susceptibility in efflux proficient and deficient $P$. aeruginosa

\begin{tabular}{|c|c|c|c|c|}
\hline \multirow[t]{2}{*}{ Compound } & \multirow[t]{2}{*}{ Structure } & \multicolumn{2}{|c|}{ BLI concentration to restore IMI $(\mu \mathrm{g} / \mathrm{mL})$} & \multirow{2}{*}{$\begin{array}{l}\text { Fold } \\
\text { differential }^{b}\end{array}$} \\
\hline & & MB6477 efflux-wt ${ }^{a}$ & $\overline{\text { MB6476 efflux-del }}{ }^{a}$ & \\
\hline DABCO \#1 & & $>100$ & 12.5 & $>8$-fold \\
\hline $\mathrm{DABCO} \# 2$ & & 50 & 3.125 & 16-fold \\
\hline DABCO \#3 & & 12.5 & 6.25 & 2 -fold \\
\hline Relebactam & & 6.25 & 3.125 & 2 -fold \\
\hline
\end{tabular}

BLI $\beta$-lactamase inhibitor, DABCO diazabicyclooctane, IMI imipenem

${ }^{a}$ MB6477 $n f x C$, wild-type for other efflux pumps, spontaneous OprD deletion; MB6476 $n f x C, \Delta[$ MexAB-OprM] $\Delta[$ MexCD-OprJ] $\Delta$ [MexXY] $\Delta[$ MexJKL] $\Delta[$ MexHI$\mathrm{OpmD}] \Delta[\mathrm{OpmH}])$

${ }^{b}$ Differential between the concentrations required to restore susceptibility to imipenem at $4 \mu \mathrm{g} / \mathrm{mL}$, expressed as the BLI concentration against $\mathrm{MB} 6477$ divided by the BLI concentration against MB6476

Table 2 shows the BLI concentration required to restore imipenem susceptibility in the wild-type efflux-proficient strain of $P$. aeruginosa (MB6477) and in the isogenic efflux-deficient strain (MB6476), for relebactam and for 3 other representative DABCO BLI (relebactam analogues; see Table 2 for molecular structure), which were chosen for illustrative purposes only. BLI compound 1 and BLI compound 2 were required in greater concentration (> 8-fold and 16-fold, respectively) in the effluxproficient strain than the efflux-deficient strain to restore imipenem susceptibility, while neither relebactam nor BLI compound 3 required notably higher concentrations in the efflux-proficient versus the efflux-deficient strain (only a 2-fold difference) and therefore did not appear to be subject to efflux.

\section{Intrinsic antibacterial and inoculum effect}

Relebactam demonstrated no intrinsic antibacterial activity when tested alone against 109 clinical isolates of $P$. aeruginosa in concentrations as high as $64 \mu \mathrm{g} / \mathrm{mL}$.
The MIC for relebactam for all isolates in that analysis was $>64 \mu \mathrm{g} / \mathrm{mL}$.

A change in $P$. aeruginosa inocula to either one log less than or greater than the standard inoculum of $5 \times 10^{5} \mathrm{CFU} / \mathrm{mL}$ did not have any apparent effect on MIC values of either imipenem or imipenem combined with $4 \mu \mathrm{g} / \mathrm{mL}$ relebactam (Additional file 3: Table S3). This was the case for all 3 isolates examined, whether or not they produced constitutive or inducible AmpC and whether or not they possessed a functional OprD.

\section{In vitro activity of imipenem versus IMI/REL in clinical isolates}

An evaluation of imipenem and IMI/REL susceptibility from the Study for Monitoring Antimicrobial Resistance Trends (SMART) global surveillance program showed little change in their susceptibility profiles from 2009 to 2016. In $2009,68 \%$ of all $P$. aeruginosa isolates $(n=993)$ collected in the SMART surveillance program were susceptible to imipenem, and that proportion increased to 


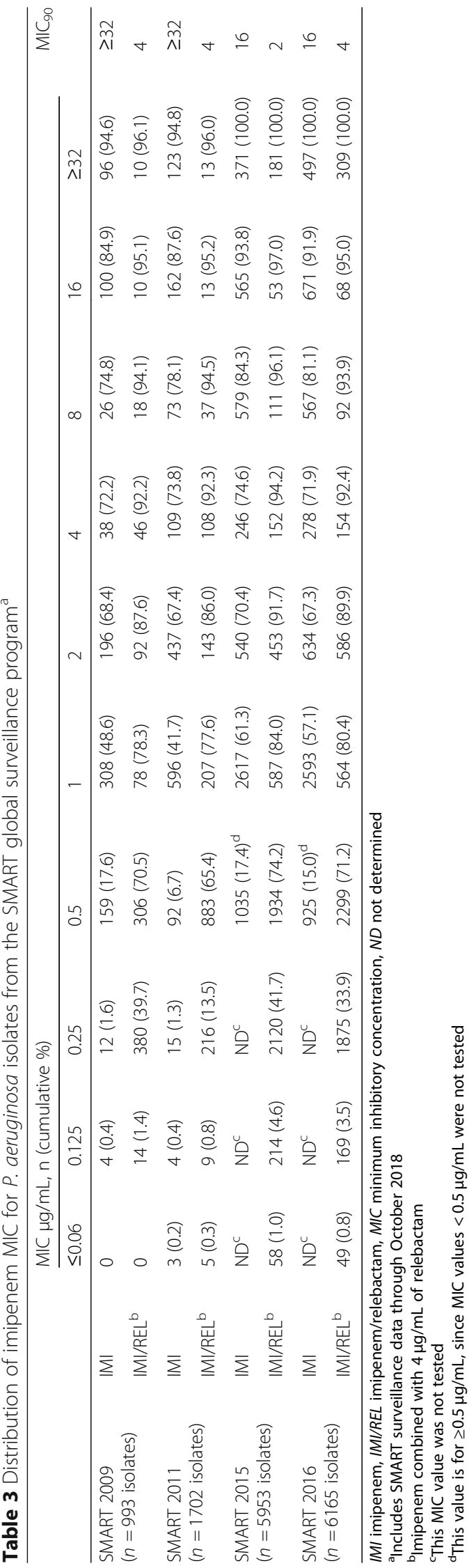


$88 \%$ with the addition of $4 \mu \mathrm{g} / \mathrm{mL}$ of relebactam to imipenem (Table 3). In 2011, 67\% of all $P$. aeruginosa isolates $(n=1702)$ from SMART were imipenem-susceptible, increasing to $86 \%$ in combination with $4 \mu \mathrm{g} / \mathrm{mL}$ relebactam (Table 3). In $2015,70 \%$ of all $P$. aeruginosa isolates $(n=5953)$ were susceptible to imipenem, increasing to $92 \%$ in combination with $4 \mu \mathrm{g} / \mathrm{mL}$ relebactam. Finally, in $2016,67 \%$ of all $P$. aeruginosa isolates $(n=6165)$ collected in the SMART surveillance program were susceptible to imipenem, and that proportion increased to $90 \%$ with the addition of $4 \mu \mathrm{g} / \mathrm{mL}$ of relebactam to imipenem (Table 3). The mode MIC values in the absence and presence of relebactam, respectively, were 1 and 0.25 in 2009 and 2015 and 1 and 0.5 in 2011 and 2016. Correspondingly, the $\mathrm{MIC}_{90}$ in the absence and presence of relebactam, respectively, was $\geq 32 \mu \mathrm{g} / \mathrm{mL}$ and $4 \mu \mathrm{g} / \mathrm{mL}$ in both 2009 and 2011, and was $16 \mu \mathrm{g} / \mathrm{mL}$ and $2 \mu \mathrm{g} / \mathrm{mL}$ in 2015 and $16 \mu \mathrm{g} / \mathrm{mL}$ and $4 \mu \mathrm{g} / \mathrm{mL}$ in 2016. The distribution of MIC values was similar between each of the 4 years (Table 3 ).

At the time of analysis of the shift in imipenem MIC values, there were 4650 imipenem-NS isolates pooled from all sources (Fig. 2a) and 9609 imipenem-susceptible isolates from SMART 2009, 2011, 2015, and 2016 (Fig. 2b). For the imipenem-NS isolates, the MIC range was 4 to $>128 \mu \mathrm{g} / \mathrm{mL}$ for imipenem alone and 0.06 to $>128 \mu \mathrm{g} / \mathrm{mL}$ for IMI/REL; the mode MIC values were $16 \mu \mathrm{g} / \mathrm{mL}$ and $2 \mu \mathrm{g} / \mathrm{mL}$, respectively, equaling an 8 fold shift. Conversely, in imipenem-susceptible isolates, the MIC range (mode) was 0.03 to $2 \mu \mathrm{g} / \mathrm{mL}(1 \mu \mathrm{g} / \mathrm{mL})$

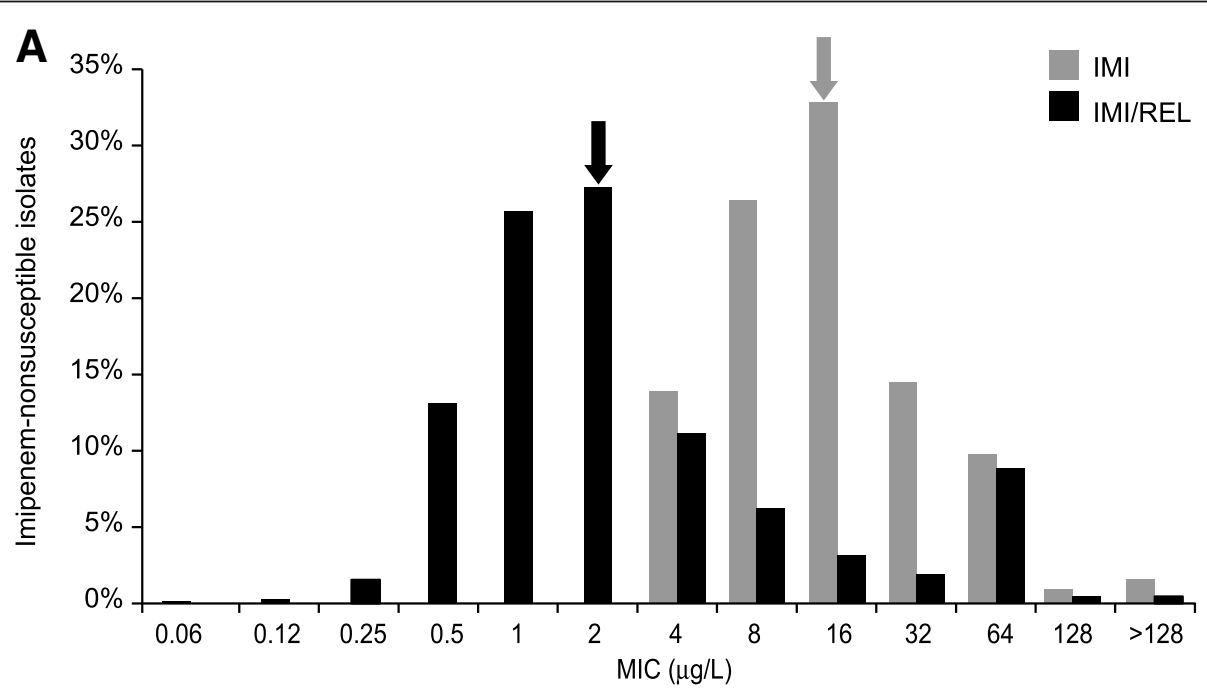

B

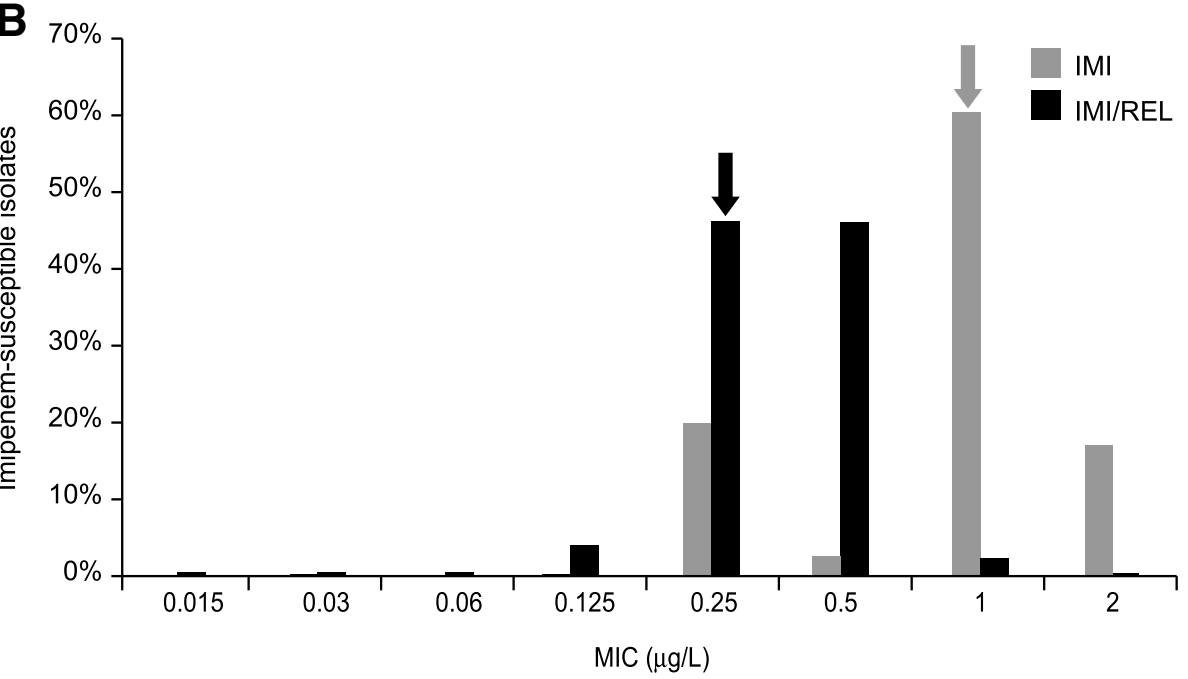

Fig. 2 Shift in imipenem MIC values for a imipenem-NS $(n=4650)$ and $\mathbf{b}$ imipenem-susceptible $(n=9609)$ isolates. ${ }^{\text {a }}$ Arrows indicate the mode MIC values for imipenem alone and imipenem combined with $4 \mu \mathrm{g} / \mathrm{mL}$ of relebactam. IMI: imipenem; IMI/REL: imipenem/relebactam; MIC: minimum inhibitory concentration; NS: non-susceptible. ${ }^{a}$ Excludes SMART surveillance data from China and India (2015 and 2016) and Vietnam (2015) due to late inclusion of the data in the analysis 
with imipenem alone and 0.015 to $2 \mu \mathrm{g} / \mathrm{mL}(0.25 \mu \mathrm{g} / \mathrm{mL})$ with IMI/REL, for a 4-fold shift in mode MIC.

\section{Molecular characterization of non-susceptibility to IMI/ REL in clinical isolates}

In total, 3747 imipenem-NS isolates underwent molecular profiling for $\beta$-lactamases, of which 1200 (32\%) were not restored to imipenem susceptibility in the presence of relebactam at $4 \mu \mathrm{g} / \mathrm{mL}$. In general, the higher the imipenem MIC value of isolates that were not susceptible to the combination of imipenem plus relebactam, the more likely they were to encode class B $\beta$-lactamases (ie, metallo- $\beta$ lactamases [MBLs]): at an IMI/REL MIC of $4 \mu \mathrm{g} / \mathrm{mL}$ only $3 \%$ of isolates contained a gene encoding an MBL, but this proportion increased with each doubling of the MIC, reaching $92 \%$ at $64 \mu \mathrm{g} / \mathrm{mL}$ (Table 4). In fact, a gene encoding an MBL was found in 506/1200 (42\%) of all isolates NS to the combination (Table 4). In comparison, $222 / 1200(19 \%)$ of all isolates NS to the combination encoded a class A enzyme and a Pseudomonas-derived cephalosporinase (PDC) allele only. A total of 133/1200 (11\%) isolates encoded a class A GES enzyme in addition to PDC, and was more commonly found in isolates with IMI/REL MICs of 8 to $32 \mu \mathrm{g} / \mathrm{mL}$. The class A GES family of $\beta$-lactamases in $P$. aeruginosa was observed worldwide, but was most common in Latin America $(n=57)$ and Europe $(n=51)$; other locations included Africa $(n=20)$, the Middle East $(n=12)$, the South Pacific $(n=5)$, Asia $(n=$ $4)$, and North America $(n=3)$. Both ESBL ${ }^{(\mathrm{e})}$ and carbapenemase $^{(\mathrm{c})}$ alleles of GES were found in susceptible isolates $\left(\mathrm{GES}-1^{\mathrm{e}},-2^{\mathrm{c}},-5^{\mathrm{c}},-7^{\mathrm{e}},-9^{\mathrm{e}}\right.$, and -29$)$ as well as those which were NS $\left(\mathrm{GES}-2^{\mathrm{c}},-5^{\mathrm{c}},-7^{\mathrm{e}},-9^{\mathrm{e}},-19^{\mathrm{e}},-20^{\mathrm{c}},-26\right)$. A total of 472/1200 (39\%) encoded AmpC only (all of which encoded PDC, and 2 additionally encoded a plasmid-mediated AmpC). Of note, the proportion of isolates encoding only PDC decreased with imipenem MIC doubling, an inverse relationship with respect to those isolates encoding MBLs. Class D enzymes were not detected in any of the SMART isolates that were NS to IMI/REL.

An exploratory analysis was conducted to see if there were any obvious contributions of PDC sequence to imipenem or IMI/REL susceptibility. Of the 2691 isolates from SMART 2011, 2015, and 2016 that possessed only PDC alleles and no other detected $\beta$-lactamase gene, relebactam restored susceptibility to 2283 isolates (85\%). The MIC range, $\mathrm{MIC}_{50}$, and $\mathrm{MIC}_{90}$ for imipenem and IMI/REL by PDC allele are shown in the online supplement (Additional file 3: Table S4). No relationship was observed between PDC alleles and either imipenem (Additional file 4: Figure S1A) or IMI/REL MIC values (Additional file 4: Figure S1B). The majority of PDC alleles had alanine at position 105, and only 3 (PDC-1, -6, and -98) had threonine. $\mathrm{MIC}_{50}$ and $\mathrm{MIC}_{90}$ values for IMI and IMI/REL were mostly similar regardless of the residue at this location.

\section{Discussion}

These in vitro studies using surveillance and challenge panels demonstrate that the novel BLI relebactam, when combined with the carbapenem imipenem, has the potential to overcome key mechanisms of imipenem resistance in $P$. aeruginosa and could thus restore imipenem susceptibility against many MDR strains of this pathogen. Relebactam was found to have no intrinsic activity against $P$. aeruginosa and no inoculum effect. Enzymology studies showed relebactam to be a potent, mechanism-based inhibitor of $P$. aeruginosa AmpC, binding to the enzyme with low to sub- $\mu \mathrm{M}$ initial affinity, followed by efficient

Table 4 Summary of $P$. aeruginosa isolates from SMART $(N=1200)$ NS to IMI/REL ${ }^{a, b}$

\begin{tabular}{|c|c|c|c|c|c|c|c|c|}
\hline \multirow{2}{*}{$\begin{array}{l}\mathrm{MIC}^{\mathrm{C}}(\mu \mathrm{g} / \\
\mathrm{mL})\end{array}$} & \multirow[t]{2}{*}{$\mathrm{N}$} & \multicolumn{5}{|l|}{ Class A } & \multirow{2}{*}{$\begin{array}{l}\text { Class B } \\
\text { Any MBL }\end{array}$} & \multirow{2}{*}{$\begin{array}{l}\text { Class C } \\
\text { AmpC only }\end{array}$} \\
\hline & & PER & GES & VEB & Other ESBL & KPC & & \\
\hline 4 & 313 & $12(4 \%)$ & $9(3 \%)$ & $18(6 \%)$ & $8(3 \%)$ & $3(1 \%)$ & $9(3 \%)$ & $254(81 \%)$ \\
\hline 8 & 239 & $4(2 \%)$ & 49 (21\%) & $7(3 \%)$ & $3(1 \%)$ & $5(2 \%)$ & $29(12 \%)$ & $142(59 \%)$ \\
\hline 16 & 128 & - & $37(29 \%)$ & $1(1 \%)$ & $3(2 \%)$ & $9(7 \%)$ & $31(24 \%)$ & $47(37 \%)$ \\
\hline 32 & 84 & - & $26(31 \%)$ & - & - & $6(7 \%)$ & $36(43 \%)$ & $16(19 \%)$ \\
\hline 64 & 404 & - & $12(3 \%)$ & $1(<1 \%)$ & - & $9(2 \%)$ & $370(92 \%)$ & $12(3 \%)$ \\
\hline 128 & 14 & - & - & - & - & - & $14(100 \%)$ & - \\
\hline$>128$ & 18 & - & - & - & - & - & $17(94 \%)$ & $1(6 \%)$ \\
\hline \multicolumn{2}{|c|}{ Total number of isolates } & 16 & 133 & 27 & 14 & 32 & 506 & 472 \\
\hline
\end{tabular}

ESBL extended-spectrum $\beta$-lactamase, IMI/REL imipenem/relebactam, KPC Klebsiella pneumoniae carbapenemase, MBL metallo- $\beta$-lactamase, MIC minimum inhibitory concentration, NS non-susceptible

${ }^{a}$ Class D enzymes were not detected in any of the isolates collected

bIncludes SMART 2009, 2011, 2015, and 2016 data. Approximately 100 isolates possessed more than one acquired $\beta$-lactamase. For purposes of this table, each of these isolates was only counted once; the specific category each isolate was assigned to was based on the following algorithm: MBL > KPC > GES > other ESBL

IImipenem minimum inhibitory concentration in the presence of $4 \mu \mathrm{g} / \mathrm{mL}$ of relebactam

IIsolates that only encoded AmpC, and not any of the other studied $\beta$-lactamases. All 472 isolates contained a gene for chromosomal PDC and 2 isolates also that contained a gene for a plasmid-borne AmpC (ie, FOX-14 and DHA-1); both of these isolates had an imipenem/relebactam MIC of $8 \mu \mathrm{g} / \mathrm{mL}$ 
acylation (on the order of minutes). The acylated enzyme/ inhibitor complex was shown to undergo slow intramolecular deacylation, reverting back to the non-covalent enzyme/inhibitor complex and resulting in an overall target engagement time of $>1.5 \mathrm{~h}$. Furthermore, the acylated complex did not appear to undergo appreciable destructive hydrolysis by intermolecular water-mediated deacylation, yielding a turnover number near unity (ie, approaching that of an irreversible inhibitor).

Additional in vitro analyses with $>14,000$ isolates showed that $89 \%$ of all $P$. aeruginosa isolates were susceptible to the combination of imipenem with relebactam at $4 \mu \mathrm{g} / \mathrm{mL}$ using current Clinical and Laboratory Standards Institute (CLSI) breakpoints for imipenem, including $68 \%$ of all isolates that were not susceptible to imipenem alone.

Our studies confirmed the previously reported ability of relebactam to inhibit class $C \beta$-lactamases in $P$. aeruginosa (relebactam is also known to inhibit class A $\beta$-lactamases) [48]. This is a noteworthy finding, given that overexpression of AmpC (a class $\mathrm{C}$ enzyme) in conjunction with decreased membrane permeability to imipenem is an important mechanism conferring imipenem nonsusceptibility to $P$. aeruginosa [41-44]. Although some BLI are subject to efflux in $P$. aeruginosa (eg, avibactam) [53], relebactam was purposefully designed to avoid this issue. Our experiments showed that relebactam was not affected by efflux at basal levels of efflux pump expression. Parallel results with relebactam and various analogues suggest that the presence of a positively charged side chain attached to the DABCO core may be the structural basis for avoiding efflux. Relebactam and BLI compound 3, which were not subject to efflux in our experiments, both possess piperidine residues, which would be protonated (and hence, positively charged) at physiological $\mathrm{pH}$. Conversely, BLI compounds 1 and 2 are less basic and would not be protonated, thus possessing a neutral charge at physiological $\mathrm{pH}$.

Furthermore, susceptibility to IMI/REL was also unaffected by RND efflux pump overexpression, demonstrating that relebactam is not a substrate of any key RND efflux pumps. This result is clinically relevant, because such overexpression is often selected as a resistance mechanism to various antibacterial agents (eg, the carbapenem meropenem). In previous genetic studies, imipenem was shown conclusively not to be a substrate for any of the RND efflux pumps in $P$. aeruginosa, unlike the betamethyl carbapenem meropenem. In $P$. aeruginosa, meropenem is a substrate for mexAB/OprM, mexCD/OprJ, and mexEF/OprN, while there is no effect on imipenem by any combination of RND pumps [54, 55]. This was confirmed by our experiments. However, there can be effects on imipenem MIC values when efflux pump genes are regulated concomitantly with genes whose expression affects imipenem $\mathrm{MIC}$ values. For example, an $n f x B$ mutation results in overexpression of mexCD/OprJ and an $n f x C$ mutation in overexpression of mexEF/OprN. Greater susceptibility to imipenem in $n f x B$ mutants was found to be a result of concomitant reduction in AmpC expression [52]. Increased imipenem MIC values in $n f x C$ mutants are correlated with the action of the MexT activator via a concomitant reduction in $\mathrm{OprD}$ expression, rather than the overexpression of mexEF/OprN [56].

AmpC-mediated resistance to imipenem in $P$. aeruginosa is multi-factorial, depending on both loss of the outer membrane entry porin OprD and high-level expression of the chromosomally-encoded AmpC enzyme. Neither OprD porin loss in the absence of $\mathrm{AmpC}$ induction or derepression, nor AmpC constitutive expression without concomitant loss of the OprD porin will result in imipenem MIC values over the susceptibility breakpoint [57]. However, AmpC expression influences the imipenem MIC even in OprD-proficient isolates, as evidenced by the reduction in imipenem MIC in the presence of relebactam. This phenocopies genetic results seen with an isogenic strain set of $P$. aeruginosa where imipenem MIC values varied upon $\mathrm{AmpC}$ overexpression or deletion within the context of OprD proficiency or deficiency [57]. Imipenem is an inducer of $\mathrm{AmpC}$, but is fairly stable to its hydrolysis, which explains why frank resistance does not occur until both entry of imipenem is limited and enzymatic activity is enhanced by mass action [58].

Since neither imipenem nor relebactam are subject to efflux, inhibition of the chromosomal AmpC enzyme by relebactam will restore susceptibility to many MDR isolates of $P$. aeruginosa, including those with overexpression of efflux pumps, as long as these isolates do not possess $\beta$-lactamases not inhibited by relebactam (eg, MBLs, some GES enzymes, and some class D carbapenemases). Overall, the inhibition of AmpC by relebactam in vitro was in agreement with the restoration of imipenem activity against imipenem-resistant strains of $P$. aeruginosa seen in our analyses. However, some isolates producing only a chromosomally encoded AmpC enzyme were not susceptible to the combination. Because PDC alleles did not impact imipenem and IMI/REL MIC values, it is likely that these isolates expressed a particularly high amount of PDC, thus influencing the ability of relebactam to restore imipenem susceptibility in these isolates, as reported previously [59]. It is also possible that some isolates could express unknown/undetected $\beta$ lactamases or imipenem resistance mechanisms. In addition, a recent analysis showed that the GES enzyme may also contribute to non-susceptibility to the combination, and attributed the resistance to IMI/REL to the expression of both GES and OXA in $2 P$. aeruginosa clinical isolates [60]. In our study, GES enzymes were seen among both IMI/REL susceptible and NS isolates. The amino acid 
at position 170 has been implicated as important for the spectrum of hydrolysis by GES [61]. We observed a diversity of GES enzymes with ESBL or carbapenemase characteristics across susceptible and NS isolates.

No influence of the sequence of PDC was observed among the clinical isolates examined. While RodriguezMartinez and colleagues observed that a mutation of the amino acid at position 105 from threonine to alanine increased the MIC to imipenem alone, it should be noted that this observation was made in isogenic strains of $P$. aeruginosa, and clinical susceptibility also depends on expression level [62]. In the present study, of the 2410 isolates examined with more than 10 representatives of any one PDC allele, only 3 alleles (PDC-1, -6 , and -98; $n=335$ ) possessed threonine at position 105 , whereas the vast majority possessed the T105A substitution, and the $\mathrm{MIC}_{50 / 90}$ and MIC range were not any higher than those alleles with alanine at position 105 .

Other novel BLI approved or in late-stage clinical development include avibactam and vaborbactam. It is important to understand how these compounds differ in their activity against Pseudomonas spp. when combined with various $\beta$-lactam partners, and our data are useful in furthering this understanding. Similar to relebactam, avibactam is a DABCO inhibitor that potently inhibits class $\mathrm{A}$ and class $\mathrm{C}$ enzymes; previously presented data suggest that intact avibactam is recreated after initial binding to a susceptible $\beta$-lactamase and thus able to inhibit additional $\beta$-lactamase molecules [63]. We observed the same with relebactam in our enzymology studies (Fig. 1), but for both avibactam and relebactam the reaction time scale is probably too long for this effect to be biologically and clinically meaningful. Avibactam has been approved for the treatment of gram-negative infections in combination with the third-generation, antipseudomonal cephalosporin ceftazidime, and currently also is being investigated in combination with aztreonam. While aztreonam-avibactam likely has no utility in the treatment of $P$. aeruginosa [64], ceftazidime-avibactam is already approved for this indication, with recent surveillance showing $>95 \%$ of $P$. aeruginosa isolates to be susceptible $[13,30,65]$. On the other hand, some investigators have reported up to $40 \%$ resistance to ceftazidime-avibactam in MDR P. aeruginosa [66], and another cephalosporin-BLI combination (ie, ceftolozanetazobactam) has been shown to be more active against carbapenem-resistant $P$. aeruginosa in vitro $[67,68]$. Ceftolozane-tazobactam may therefore be preferable to ceftazidime-avibactam for treating MDR $P$. aeruginosa [69]. The carbapenem-BLI combination of meropenem-vaborbactam does not appear to have improved in vitro activity against $P$. aeruginosa compared with its carbapenem component alone [70]. It can therefore be expected that meropenem-vaborbactam would possess only limited clinical utility in the treatment of MDR $P$. aeruginosa.

Thus far, the combination of imipenem and relebactam has shown promising results in both phase 2 and phase 3 clinical studies in complicated urinary tract infection and complicated intra-abdominal infection, including among patients with $P$. aeruginosa infections [71-73]. However, both phase 2 studies broadly enrolled patients regardless of baseline pathogen susceptibility profiles and were not limited to those with MDR causative pathogens. The clinical efficacy of IMI/REL was supported by a recent phase 3 study in patients with imipenem-resistant bacterial infection [73], and further confirmation is sought from another phase 3 study in patients with bacterial pneumonia that was recently completed (NCT02493764).

\section{Conclusions}

Relebactam was found to be a potent, slowly dissociated inhibitor of $P$. aeruginosa AmpC, with a practical effectiveness of inhibition approaching that of an irreversible inactivator. Almost $90 \%$ of all $P$. aeruginosa isolates analyzed $(>14,000)$ were susceptible to the combination of imipenem with $4 \mu \mathrm{g} / \mathrm{mL}$ relebactam, including about $70 \%$ of all imipenem-NS isolates. We identified specific properties of relebactam (ie, the lack of an inoculum effect and the lack of efflux) that likely contribute to the in vitro efficacy of this agent in restoring imipenem susceptibility. In our data set, relebactam was particularly effective in $P$. aeruginosa strains encoding AmpC (class C) $\beta$-lactamases, regardless of the underlying PDC allele. Conversely, isolates not susceptible to IMI/REL at current imipenem breakpoints frequently contained class B MBLs. The combination of imipenem with relebactam may therefore have potential in the treatment of carbapenem-resistant $P$. aeruginosa infections, with the exception of strains carrying class B or class D carbapenemases.

\section{Methods \\ Enzymology studies \\ Determination of AmpC inhibition kinetic parameters}

AmpC PDC-1 was monitored in a continuous homogeneous biochemical assay via hydrolysis of a colorimetric nitrocefin substrate in 384-well plates (for PDC-1 cloning and purification, see Additional file 1); the assay buffer used was $0.1 \mathrm{M} \mathrm{KH}_{2} \mathrm{PO}_{4}$, pH 7.0 with $0.005 \%$ Tween 20 . Relebactam (in concentrations ranging from $0.61 \mathrm{nM}$ to $20,000 \mathrm{nM}$ ) and $200 \mu \mathrm{M}$ nitrocefin were dispensed first and AmpC (30 pM) was subsequently added to start the reaction. The absorbance increase at $490 \mathrm{~nm}$ was immediately and continuously monitored for $2 \mathrm{~h}$. Inactivation kinetic parameters were determined by global progress 
curve analysis of the entire kinetic data set using a validated and previously published experimental design (Additional file 2: Figure S1) [74-76].

\section{Determination of relebactam turnover number}

$P$. aeruginosa AmpC (PDC-1) and serially diluted relebactam were pre-incubated at $200 \times$ final concentrations (300 pM P. aeruginosa AmpC and $14.7 \mathrm{pM}$ to $30,000 \mathrm{pM}$ relebactam) for 2 and $24 \mathrm{~h}$ and subsequently diluted to $1 \times$ concentrations and assayed under saturating nitrocefin concentration $(200 \mu \mathrm{M})$. The residual (ie, quickly recoverable) enzymatic activity was monitored continuously by absorbance measurement at $490 \mathrm{~nm}$ for $10 \mathrm{~min}$. The turnover number was determined by extrapolation to $0 \%$ activity from plots of the initial linear portion of $\%$ activity versus inhibitor/enzyme ratio.

\section{Isolate sources}

Unique clinical isolates of $P$. aeruginosa were obtained from 4 different sources, with no overlap: (a) a challenge panel of imipenem-NS isolates $(n=108)$ curated at Merck \& Co., Inc. (Kenilworth, NJ, USA) [77]; (b) a challenge panel of imipenem-NS isolates $(n=185)$ curated at Eurofins (Chantilly, VA, USA) [78]; (c) the Study for Monitoring Antimicrobial Resistance Trends (SMART) global surveillance program in the years 2009, 2011, 2015, and 2016 ( $n=14,813$ total isolates, including 4501 imipenem-NS isolates as of October 2018) [10]; and (d) all imipenem-NS isolates from a previously published surveillance study from New York, NY, USA $(n=144)$ [45]. Details of the 4 isolate sources are found in the online supplement (Additional file 3: Table S1). These isolate sources were chosen to provide a broad distribution of geographic areas and imipenem MIC values.

\section{Molecular epidemiology}

Imipenem-NS isolates from SMART 2009, 2011, 2015, and 2016 were analyzed for the presence of the following $\beta$-lactamases by an established method using multiplex polymerase chain reaction (PCR) followed by full-gene DNA sequencing [79-81]: class A (SHV, TEM, CTX-M, VEB, PER, GES, and KPC); class B (GIM, IMP, NDM, $\mathrm{SPM}$, and VIM); class $C$ (acquired, plasmid-mediated AmpC: ACC, ACT, CMY, DHA, FOX, MIR, and MOX; and intrinsic, chromosomal AmpC: $\mathrm{PDC}$ ); and class $\mathrm{D}$ (OXA-24/-40-like). PDC sequences [82] were retrieved from Genbank by searching the protein database for the keyword "PDC- . Retrieved sequences were aligned with the Clustal Omega software (EMBL-EBI, Hinxton, United Kingdom) [83] using the default protein settings. The potential relationships of imipenem and IMI/REL MIC values to PDC sequence were explored by determining the $\mathrm{MIC}_{50}$ and $\mathrm{MIC}_{90}$ for all isolates possessing only a PDC allele and no other detected $\beta$-lactamase; the $\mathrm{MIC}_{50}$ and $\mathrm{MIC}_{90}$ values associated with PDC alleles present in $\geq 10$ isolates were mapped onto a circular dendrogram. The resulting dendrogram was visualized using the Dendroscope 3 software (Universität Tübingen, Tübingen, Germany) [84]. Molecular data were available for all imipenem-NS isolates collected in 2015 and 2016. For 2009, selected imipenem-NS isolates underwent molecular characterization. For 2011, only isolates NS to the combination of imipenem and relebactam $4 \mu \mathrm{g} / \mathrm{mL}$ underwent molecular characterization.

\section{Relebactam efflux studies}

\section{Efflux studies using isogenic mutant strains}

To assess whether relebactam and 3 additional DABCO analogs chosen for illustrative purposes were subject to efflux, we isolated $o p r D^{-}$mutants in an isogenic set of P. aeruginosa strains: (a) a wild-type strain (CB046, also known as MB5919) expressing baseline levels of efflux pumps and (b) a mutant strain (CB1101, also known as MB5890) with multiple deletions of genes encoding major RND efflux pump proteins ( $\Delta[$ mexAB-oprM $] \Delta[$ mexCDopr] $\Delta[$ mexXY] $\Delta[$ mexJKL] $\Delta[$ mexHI-opmD] $\Delta[$ opmH]) $[85,86]$. Of note, it was later determined that the background of this strain pair carried an 8-base pair deletion in mexT, which has previously been described as an $n f x C$ type mutation that in other $P$. aeruginosa strains results in overexpression of the MexEF-OprN efflux pump and repressed OprD porin production, and raised the imipenem MIC slightly [56, 87]. The oprD $D^{-}$mutants of both strains were obtained by selection for spontaneous imipenem resistance on agar plates containing concentrations of imipenem above the MIC, using a previously described method [88]. Gel electrophoresis of outer membrane proteins was used to confirm loss of the band corresponding to OprD. The resulting mutant strains, MB6477 $\left(\mathrm{OprD}^{-}\right.$, wild-type efflux-proficient) and $\mathrm{MB} 6476\left(\mathrm{OprD}^{-}\right.$, multiefflux-deficient), were then used to determine if these BLI were subject to efflux by calculating the fold differential between the concentrations required in broth microdilution testing to reduce the imipenem MIC to $4 \mu \mathrm{g} / \mathrm{mL}$, expressed as the BLI concentration required for MB6477 divided by the BLI concentration required for MB6476 for each BLI compound tested.

\section{Construction and antibiogram evaluation of $P$. aeruginosa RND overexpression strains}

A second set of efflux studies was conducted to determine if susceptibility to relebactam might be affected by multidrug efflux pump overexpression, a common resistance mechanism in MDR $P$. aeruginosa. Four different strains, each overexpressing one of the major RND efflux pumps (ie, MexAB, MexCD, MexEF, and MexXY), were constructed from MB6477 by knocking out the transcriptional regulators $\operatorname{mex} R, n f x B, \operatorname{mex} L$, and $\operatorname{mex} Z$, 
respectively. Primer sequences for these experiments are listed in the online supplement (Additional file 3: Table S2). Flanking regions of each gene comprising $500 \mathrm{bp}$ upstream and 500 bp downstream were amplified using primer pairs $\mathrm{P} 1 / \mathrm{P} 2$ and $\mathrm{P} 3 / \mathrm{P} 4$ for $\operatorname{mexR}, \mathrm{P} 5 / \mathrm{P} 6$ and $\mathrm{P} 7 / \mathrm{P} 8$ for $n f x B, \mathrm{P} 9 / \mathrm{P} 10$ and P11/P12 for mexL, and P13/P14 and P15/P16 for mexZ. Subsequently, splicing by overlap extension was used to combine upstream and downstream products with external primers $\mathrm{P} 1 / \mathrm{P} 4, \mathrm{P} 5 / \mathrm{P} 8, \mathrm{P} 9 / \mathrm{P} 12$, and P13/P16 for mexR, $n f x B$, mexL, and mexZ, respectively. These complete alleles containing unmarked deletions of each transcriptional regulator were then cloned into a BamHI/PstI-digested pEX18Ap suicide vector using In-Fusion HD enzyme (Clontech, Mountain View, CA). After DNA sequencing (performed by Genewiz Inc., South Plainfield, NJ) to confirm the correct alleles had been made, plasmids were mobilized from E. coli RHO3 into MB5919 and MB6477 using previously published methods [89]. To resolve cointegrants to double crossover mutants, single colonies were restreaked onto lysogeny no-salt broth (10 $\mathrm{g} / \mathrm{L}$ tryptone, $5 \mathrm{~g} / \mathrm{L}$ yeast extract) with $10 \%$ (wt/vol) sucrose to select for loss of the $s a c B$-containing vector backbone. Resulting colonies were screened by PCR using primers P17/P18, P19/P20, P21/P22, and $\mathrm{P} 23 / \mathrm{P} 24$ for $\operatorname{mexR}, n f x B$, mexL, and mexZ, respectively, to identify those with an amplified DNA product that was reduced in size compared to the wild-type parental strains. Constructs containing the desired deletion were confirmed by sequencing across the respective gene-yielding strains MB5919 $\Delta m e x R, M B 5919 \Delta n f x B$,

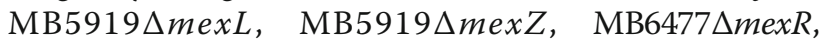

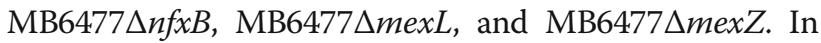
these experiments, all DNA was purified using the QIAprep spin miniprep kit and QIAquick gel-extraction kit (Qiagen, Valencia, CA). Phusion high-fidelity polymerase and restriction enzymes PstI and BamHI were from New England BioLabs (Ipswich, MA). Electroporation was performed on a Gene Pulser II electroporator with Gene Pulser cuvettes (Bio-Rad, Hercules, CA).

Antibiograms, determined by 2 -fold serial broth microdilution, were obtained for each of the 4 RND overexpression strains, as well as for the isogenic mutant strains MB6477 and MB6476, using aztreonam, ceftazidime, chloramphenicol, levofloxacin, and meropenem, which are all known to be affected by efflux in $P$. aeruginosa to varying degrees $[49,50]$, and which served as controls to confirm that the engineered strains were efflux overexpressors. After the phenotypes of efflux overexpression were confirmed, imipenem and imipenem plus $4 \mu \mathrm{g} / \mathrm{mL}$ relebactam were tested subsequently to see if the MICs were affected by efflux.

\section{Microbiology studies}

Antibacterial susceptibility testing for each $P$. aeruginosa isolate obtained from the four isolate sources listed above was performed using standard CLSI broth microdilution methodology using cation-adjusted Mueller Hinton broth [90, 91]. Imipenem MIC values were assessed in both presence and absence of relebactam at a fixed concentration of $4 \mu \mathrm{g} / \mathrm{mL}$ in combination with 2 -fold dilutions of imipenem. The in vitro susceptibility concentration of $4 \mu \mathrm{g} / \mathrm{mL}$ relebactam was chosen based on an average total plasma concentration of $4.94 \mu \mathrm{g} / \mathrm{mL}$ relebactam (free concentration $=3.85 \mu \mathrm{g} / \mathrm{mL}$ ) achieved in adults (with bodyweight $>70 \mathrm{~kg}$ ) receiving $250 \mathrm{mg}$ relebactam every $6 \mathrm{~h}$ [71]. MIC values for both imipenem and the IMI/REL combination were interpreted using current CLSI breakpoints for imipenem against $P$. aeruginosa: susceptible, $2 \mu \mathrm{g} / \mathrm{mL}$; intermediate, $4 \mu \mathrm{g} / \mathrm{mL}$; and resistant, $8 \mu \mathrm{g} / \mathrm{mL}$ [91].

Relebactam was assessed for intrinsic antibacterial activity in the Merck challenge panel ( $n=108$ isolates) by testing in 2-fold serial dilutions ranging from $0.06 \mu \mathrm{g} / \mathrm{mL}$ to $64 \mu \mathrm{g} / \mathrm{mL}$. The potential for an inoculum effect of relebactam plus imipenem was evaluated by testing in duplicate the MIC values of imipenem alone and imipenem plus relebactam $4 \mu \mathrm{g} / \mathrm{mL}$ in 3 strains of $P$. aeruginosa: (a) ATCC 27853, an imipenem-susceptible, standard reference strain of $P$. aeruginosa expressing PDC-5; (b) CL 5701 (M1405ß-con D2-4105), an imipenem-NS strain with de-repressed AmpC (PDC-5) expression and spontaneous loss of OprD [57]; and (c) CLB 24228, an imipenem-NS strain with inducible AmpC expression (PDC-16). Each strain was tested at the standard inoculum of $5 \times 10^{5}$ colony forming units $(\mathrm{CFU}) / \mathrm{mL}$, as well as at inocula lower $\left(5 \times 10^{4}\right)$ and greater $\left(5 \times 10^{6}\right)$ than the standard inoculum.

\section{Additional files}

Additional file 1: PDC-1 cloning and purification. (DOCX $13 \mathrm{~kb}$ ) Additional file 2: Figure S1. Mechanistic profiling by global progress curve analysis. (DOCX $81 \mathrm{~kb}$ )

Additional file 3: Table S1. $P$ aeruginosa isolate sources. Table S2. Primers used in the construction of $P$. aeruginosa RND-overexpressing strains. Table S3. Inoculum effect control data. Table S4. Susceptibility to imipenem and the combination of imipenem with relebactam $4 \mu \mathrm{g} / \mathrm{mL}$ by PDC allele. (DOCX $25 \mathrm{~kb}$ )

Additional file 4: Figure S1. Minimum inhibitory concentrations $\left(\mathrm{MIC}_{50 / 90}\right.$, expressed in $\mu \mathrm{g} / \mathrm{mL}$ ) for imipenem $(A)$ and imipenem with $4 \mu \mathrm{g} / \mathrm{mL}$ relebactam (B), mapped onto a dendrogram of $P$. aeruginosa PDC alleles. (PDF $1384 \mathrm{~kb}$ )

\section{Abbreviations}

BLI: $\beta$-lactamase inhibitor; bp: Base pair; CFU: Colony forming units; CLSI: Clinical and Laboratory Standards Institute; DABCO: Diazabicyclooctane; IMI/REL: Imipenem/relebactam; KPC: Klebsiella pneumoniae carbapenemase; MBL: Metallo- $\beta$-lactamase; MDR: Multidrug-resistant; MIC: Minimum inhibitory concentration; MK-7655: Relebactam; NS: Non-susceptible; OprD: Outer 
membrane porin D; PBP: Penicillin-binding protein; PCR: Polymerase chain reaction; PDC: Pseudomonas-derived cephalosporinase; RND: Resistancenodulation-cell division; XDR: Extensively drug-resistant

\section{Acknowledgements}

Medical writing and/or editorial assistance was provided by Dominik Wolf, MSc, of Merck Sharp \& Dohme Corp, a subsidiary of Merck \& Co., Inc., Kenilworth, NJ, USA (MSD), and Robert Schupp, PharmD, CMPP, of The Lockwood Group, Stamford, CT, USA. This assistance was funded by MSD. The authors would like to gratefully acknowledge: David B. Olsen (MSD) for his support in making these analyses possible; Todd Mayhood and Payal Sheth (both MSD) for their contributions to the enzymology studies; David Landman (from The State University of New York) for his role in collecting and analyzing the clinical isolates from the SUNY surveillance panel; David Livermore for his kind gift of the CL 5701 isolate; Chris Pillar (formerly of Eurofins) for his role in collecting and analyzing the clinical isolates from the Eurofins curated panel; IHMA staff for conducting the SMART surveillance program; and IHMA microbiology and molecular biology laboratory personnel for isolate testing.

The authors would also like to thank all SMART participants for their contributions to the program.

This research was presented in part at the following congresses: ECCMID 2018, Madrid, Spain; ECCMID 2015, Vienna, Austria; MAD-ID 2015, Orlando, FL, USA; ICAAC/ICC 2015, San Diego, CA, USA; ICAAC 2013, Denver, CO, USA; ICAAC 2012, San Francisco, CA, USA; IDWeek 2012, San Diego, CA, USA; and ICAAC 2010, Boston, MA, USA.

All authors are responsible for the work described in this paper. All authors were involved in at least one of the following: conception, design of work or acquisition, analysis, interpretation of data, and drafting the manuscript and/ or revising/reviewing the manuscript for important intellectual content. All authors provided final approval of the version to be published. All authors agree to be accountable for all aspects of the work in ensuring that questions related to the accuracy or integrity of any part of the work are appropriately investigated and resolved.

\section{Authors' contributions}

$K Y, C J B, R Z$, and TB contributed to the study design. KY, REP, FR, CJB, AV, SLR, $\mathrm{NNH}, \mathrm{DW}, \mathrm{MLH}, \mathrm{DS}, \mathrm{NM}$, and MRM contributed to the acquisition of data data analysis, and/or interpretation of the data. All authors reviewed and provided final approval of the version to be published.

\section{Funding}

Funding for this research and the medical writing and/or editorial assistance was provided by MSD. The sponsor was involved in the design of the study, the collection, analysis, and interpretation of study data, and the writing of the manuscript.

\section{Availability of data and materials}

The dataset(s) supporting the conclusions of this article are included within the article and its additional files. The data sharing policy of MSD, including restrictions, is available at http://engagezone.msd.com/ds_documentation.php. Requests for access to the data for this study can be submitted through the EngageZone site or via email to dataaccess@merck.com.

\section{Ethics approval and consent to participate}

Not applicable.

\section{Consent for publication}

Not applicable.

\section{Competing interests}

$\mathrm{KY}, \mathrm{REP}, \mathrm{FR}, \mathrm{CJB}, \mathrm{AV}, \mathrm{NM}$, and MRM are employees of MSD, who may own stock and/or hold stock options in the Company. SLR, NNH, DW, RZ, TB, and $\mathrm{MLH}$ (deceased) are former employees of MSD. DFS is an employee of International Health Management Associates, Inc. (IHMA), which receives funding from MSD, for the SMART surveillance program.

\section{Author details}

Merck \& Co., Inc., 2015 Galloping Hill Road MN-410, Kenilworth, NJ 07033, USA. ${ }^{2}$ HMMA, Schaumburg, IL, USA.
Received: 22 January 2019 Accepted: 20 June 2019

Published online: 04 July 2019

\section{References}

1. Savoia D. New perspectives in the management of Pseudomonas aeruginosa infections. Future Microbiol. 2014;9:917-28.

2. Ruiz L, Dominguez MA, Ruiz N, Vinas M. Relationship between clinical and environmental isolates of Pseudomonas aeruginosa in a hospital setting. Arch Med Res. 2004:35:251-7.

3. Hauser AR, Jain M, Bar-Meir M, McColley SA. Clinical significance of microbial infection and adaptation in cystic fibrosis. Clin Microbiol Rev. 2011;24:29-70

4. Burton DC, Edwards JR, Srinivasan A, Fridkin SK, Gould CV. Trends in catheter-associated urinary tract infections in adult intensive care unitsUnited States, 1990-2007. Infect Control Hosp Epidemiol. 2011;32:748-56.

5. Bagshaw SM, Laupland KB. Epidemiology of intensive care unit-acquired urinary tract infections. Curr Opin Infect Dis. 2006;19:67-71.

6. Gaynes R, Edwards JR, National Nosocomial Infections Surveillance System. Overview of nosocomial infections caused by gram-negative bacilli. Clin Infect Dis. 2005:41:848-54.

7. Karlowsky JA, Hoban DJ, Hackel MA, Lob SH, Sahm DF. Resistance among gram-negative ESKAPE pathogens isolated from hospitalized patients with intra-abdominal and urinary tract infections in Latin American countries: SMART 2013-2015. Braz J Infect Dis. 2017;21:343-8.

8. Karlowsky JA, Hoban DJ, Hackel MA, Lob SH, Sahm DF. Antimicrobial susceptibility of gram-negative ESKAPE pathogens isolated from hospitalized patients with intra-abdominal and urinary tract infections in Asia-Pacific countries: SMART 2013-2015. J Med Microbiol. 2017;66:61-9.

9. Lob SH, Badal RE, Hackel MA, Sahm DF. Epidemiology and antimicrobial susceptibility of gram-negative pathogens causing intra-abdominal infections in pediatric patients in Europe-SMART 2011-2014. J Pediatric Infect Dis Soc. 2017:6:72-9.

10. Morrissey I, Hackel M, Badal R, Bouchillon S, Hawser S, Biedenbach D. A review of ten years of the study for monitoring antimicrobial resistance trends (SMART) from 2002 to 2011. Pharmaceuticals (Basel). 2013;6:1335-46.

11. Pfaller MA, Flamm RK, Duncan LR, Mendes RE, Jones RN, Sader HS. Antimicrobial activity of tigecycline and cefoperazone/sulbactam tested against 18,386 gram-negative organisms from Europe and the Asia-Pacific region (2013-2014). Diagn Microbiol Infect Dis. 2017;88:177-83.

12. Sader HS, Castanheira M, Farrell DJ, Flamm RK, Mendes RE, Jones RN. Tigecycline antimicrobial activity tested against clinical bacteria from Latin American medical centres: results from SENTRY antimicrobial surveillance program (2011-2014). Int J Antimicrob Agents. 2016:48:144-50.

13. Sader HS, Castanheira M, Flamm RK, Huband MD, Jones RN. CeftazidimeAvibactam Activity against Aerobic Gram Negative Organisms Isolated from Intra-Abdominal Infections in United States Hospitals, 2012-2014. Surg Infect (Larchmt). 2016;17:473-8.

14. Sader HS, Farrell DJ, Castanheira M, Flamm RK, Jones RN. Antimicrobial activity of ceftolozane/tazobactam tested against Pseudomonas aeruginosa and Enterobacteriaceae with various resistance patterns isolated in European hospitals (2011-12). J Antimicrob Chemother. 2014;69:2713-22.

15. Sader HS, Farrell DJ, Flamm RK, Jones RN. Antimicrobial susceptibility of gram-negative organisms isolated from patients hospitalised with pneumonia in US and European hospitals: results from the SENTRY antimicrobial surveillance program, 2009-2012. Int J Antimicrob Agents. 2014:43:328-34

16. Sader HS, Farrell DJ, Flamm RK, Jones RN. Antimicrobial susceptibility of gram-negative organisms isolated from patients hospitalized in intensive care units in United States and European hospitals (2009-2011). Diagn Microbiol Infect Dis. 2014:78:443-8.

17. Sader HS, Farrell DJ, Flamm RK, Jones RN. Ceftolozane/tazobactam activity tested against aerobic gram-negative organisms isolated from intraabdominal and urinary tract infections in European and United States hospitals (2012). J Infect. 2014;69:266-77.

18. Gales AC, Castanheira M, Jones RN, Sader HS. Antimicrobial resistance among gram-negative bacilli isolated from Latin America: results from SENTRY antimicrobial surveillance program (Latin America, 2008-2010). Diagn Microbiol Infect Dis. 2012;73:354-60.

19. Jones RN, Kirby JT, Beach ML, Biedenbach DJ, Pfaller MA Geographic variations in activity of broad-spectrum beta-lactams against Pseudomonas 
aeruginosa: summary of the worldwide SENTRY antimicrobial surveillance program (1997-2000). Diagn Microbiol Infect Dis. 2002;43:239-43.

20. Sader HS, Huband MD, Castanheira M, Flamm RK. Pseudomonas aeruginosa antimicrobial susceptibility results from four years (2012 to 2015) of the international network for optimal resistance monitoring program in the United States. Antimicrob Agents Chemother. 2017;61:e02252-16.

21. Oliver A, Mulet $X$, Lopez-Causape C, Juan C. The increasing threat of Pseudomonas aeruginosa high-risk clones. Drug Resist Updat. 2015;21-22:41-59.

22. Buhl M, Peter $\mathrm{S}$, Willmann M. Prevalence and risk factors associated with colonization and infection of extensively drug-resistant Pseudomonas aeruginosa: a systematic review. Expert Rev Anti-Infect Ther. 2015;13:1159-70.

23. Zhanel GG, Wiebe R, Dilay L, Thomson K, Rubinstein E, Hoban DJ, et al. Comparative review of the carbapenems. Drugs. 2007;67:1027-52.

24. Papp-Wallace KM, Endimiani A, Taracila MA, Bonomo RA. Carbapenems: past, present, and future. Antimicrob Agents Chemother. 2011;55:4943-60.

25. Rodloff AC, Goldstein EJ, Torres A. Two decades of imipenem therapy. J Antimicrob Chemother. 2006;58:916-29.

26. Voor In 't Holt AF, Severin JA, Lesaffre EM, Vos MC. A systematic review and meta-analyses show that carbapenem use and medical devices are the leading risk factors for carbapenem-resistant Pseudomonas aeruginosa. Antimicrob Agents Chemother. 2014;58:2626-37.

27. El Zowalaty ME, Al Thani AA, Webster TJ, El Zowalaty AE, Schweizer HP, Nasrallah GK, et al. Pseudomonas aeruginosa: arsenal of resistance mechanisms, decades of changing resistance profiles, and future antimicrobial therapies. Future Microbiol. 2015;10:1683-706.

28. Pluss-Suard C, Pannatier A, Kronenberg A, Muhlemann K, Zanetti G. Impact of antibiotic use on carbapenem resistance in Pseudomonas aeruginosa: is there a role for antibiotic diversity? Antimicrob Agents Chemother. 2013;57:1709-13.

29. Farrell DJ, Flamm RK, Sader HS, Jones RN. Antimicrobial activity of ceftolozane-tazobactam tested against Enterobacteriaceae and Pseudomonas aeruginosa with various resistance patterns isolated in U.S. hospitals (2011-2012). Antimicrob Agents Chemother. 2013;57:6305-10.

30. Sader HS, Castanheira M, Mendes RE, Flamm RK, Farrell DJ, Jones RN. Ceftazidime-avibactam activity against multidrug-resistant Pseudomonas aeruginosa isolated in U.S. medical centers in 2012 and 2013. Antimicrob Agents Chemother. 2015;59:3656-9.

31. Jean SS, Hsueh PR, Lee WS, Yu KW, Liao CH, Chang FY, et al. Carbapenem susceptibilities and non-susceptibility concordance to different carbapenems amongst clinically important gram-negative bacteria isolated from intensive care units in Taiwan: results from the surveillance of multicentre antimicrobial resistance in Taiwan (SMART) in 2009. Int J Antimicrob Agents. 2013;41:457-62.

32. Hawser SP, Badal RE, Bouchillon SK, Hoban DJ, Hackel MA, Biedenbach DJ, et al. Susceptibility of gram-negative aerobic bacilli from intra-abdominal pathogens to antimicrobial agents collected in the United States during 2011. J Infect. 2014;68:71-6.

33. Kehl SC, Dowzicky MJ. Global assessment of antimicrobial susceptibility among gram-negative organisms collected from pediatric patients between 2004 and 2012: results from the Tigecycline evaluation and surveillance trial. J Clin Microbiol. 2015;53:1286-93.

34. Lob SH, Hackel MA, Kazmierczak KM, Hoban DJ, Young K, Motyl MR, et al. In vitro activity of imipenem-relebactam against gram-negative bacilli isolated from patients with lower respiratory tract infections in the United States in 2015 - results from the SMART global surveillance program. Diagn Microbiol Infect Dis. 2017;88:171-6.

35. Lob SH, Hackel MA, Kazmierczak KM, Young K, Motyl MR, Karlowsky JA, et al. In vitro activity of imipenem-relebactam against gram-negative ESKAPE pathogens isolated by clinical laboratories in the United States in 2015 (results from the SMART global surveillance program). Antimicrob Agents Chemother. 2017;61:e02209-16.

36. Castanheira M, Deshpande LM, Costello A, Davies TA, Jones RN. Epidemiology and carbapenem resistance mechanisms of carbapenem-non-susceptible Pseudomonas aeruginosa collected during 2009-11 in 14 European and Mediterranean countries. J Antimicrob Chemother. 2014;69:1804-14.

37. Meletis G, Vavatsi N, Exindari M, Protonotariou E, Sianou E, Haitoglou C, et al. Accumulation of carbapenem resistance mechanisms in VIM-2-producing Pseudomonas aeruginosa under selective pressure. Eur J Clin Microbiol Infect Dis. 2014;33:253-8.

38. Liu Y, Li XY, Wan LG, Jiang WY, Li FQ, Yang JH. Efflux system overexpression and decreased OprD contribute to the carbapenem resistance among extended-spectrum beta-lactamase-producing Pseudomonas aeruginosa isolates from a Chinese university hospital. Microb Drug Resist. 2013;19:463-8.

39. Wolter DJ, Lister PD. Mechanisms of beta-lactam resistance among Pseudomonas aeruginosa. Curr Pharm Des. 2013;19:209-22.

40. Fuste E, Lopez-Jimenez L, Segura C, Gainza E, Vinuesa T, Vinas M. Carbapenem-resistance mechanisms of multidrug-resistant Pseudomonas aeruginosa. J Med Microbiol. 2013;62:1317-25.

41. Meletis G, Exindari M, Vavatsi N, Sofianou D, Diza E. Mechanisms responsible for the emergence of carbapenem resistance in Pseudomonas aeruginosa. Hippokratia. 2012;16:303-7.

42. El Amin N, Giske CG, Jalal S, Keijser B, Kronvall G, Wretlind B. Carbapenem resistance mechanisms in Pseudomonas aeruginosa: alterations of porin OprD and efflux proteins do not fully explain resistance patterns observed in clinical isolates. APMIS. 2005;113:187-96.

43. Quale J, Bratu S, Gupta J, Landman D. Interplay of efflux system, ampC, and oprD expression in carbapenem resistance of Pseudomonas aeruginosa clinical isolates. Antimicrob Agents Chemother. 2006;50:1633-41.

44. Li H, Luo YF, Williams BJ, Blackwell TS, Xie CM. Structure and function of OprD protein in Pseudomonas aeruginosa: from antibiotic resistance to novel therapies. Int J Med Microbiol. 2012;302:63-8.

45. Lapuebla A, Abdallah M, Olafisoye O, Cortes C, Urban C, Landman D, et al Activity of imipenem with Relebactam against gram-negative Pathogens from new York City. Antimicrob Agents Chemother. 2015;59:5029-31.

46. Livermore DM, Warner M, Mushtaq S. Activity of MK-7655 combined with imipenem against Enterobacteriaceae and Pseudomonas aeruginosa. J Antimicrob Chemother. 2013;68:2286-90.

47. Hirsch EB, Ledesma KR, Chang KT, Schwartz MS, Motyl MR, Tam VH. In vitro activity of MK-7655, a novel beta-lactamase inhibitor, in combination with imipenem against carbapenem-resistant gram-negative bacteria. Antimicrob Agents Chemother. 2012;56:3753-7.

48. Blizzard TA, Chen H, Kim S, Wu J, Bodner R, Gude C, et al. Discovery of MK7655, a beta-lactamase inhibitor for combination with Primaxin ${ }^{(\mathrm{R})}$. Bioorg Med Chem Lett. 2014;24:780-5

49. Morita Y, Tomida J, Kawamura Y. MexXY multidrug efflux system of Pseudomonas aeruginosa. Front Microbiol. 2012;3:408.

50. Dreier J, Ruggerone P. Interaction of antibacterial compounds with RND efflux pumps in Pseudomonas aeruginosa. Front Microbiol. 2015;6:660.

51. Morita Y, Tomida J, Kawamura Y. Responses of Pseudomonas aeruginosa to antimicrobials. Front Microbiol. 2014;4:422.

52. Masuda N, Sakagawa E, Ohya S, Gotoh N, Nishino T. Hypersusceptibility of the Pseudomonas aeruginosa nfxB mutant to beta-lactams due to reduced expression of the ampC beta-lactamase. Antimicrob Agents Chemother. 2001;45:1284-6.

53. Chalhoub H, Tulkens PM, Van Bambeke F. Avibactam is a substrate for MexAB-OprM in Pseudomonas aeruginosa. In 27th European Congress of Clinical Microbiology and Infectious Diseases (ECCMID). Vienna; 2017.

54. Masuda N, Sakagawa E, Ohya S, Gotoh N, Tsujimoto H, Nishino T. Substrate specificities of MexAB-OprM, MexCD-OprJ, and MexXY-oprM efflux pumps in Pseudomonas aeruginosa. Antimicrob Agents Chemother. 2000;44:3322-7.

55. Okamoto K, Gotoh N, Nishino T. Alterations of susceptibility of Pseudomonas aeruginosa by overproduction of multidrug efflux systems, MexAB-OprM, MexCD-OprJ, and MexXY/OprM to carbapenems: substrate specificities of the efflux systems. J Infect Chemother. 2002;8:371-3.

56. Maseda H, Saito K, Nakajima A, Nakae T. Variation of the mexT gene, a regulator of the MexEF-oprN efflux pump expression in wild-type strains of Pseudomonas aeruginosa. FEMS Microbiol Lett. 2000;192:107-12.

57. Livermore DM. Interplay of impermeability and chromosomal betalactamase activity in imipenem-resistant Pseudomonas aeruginosa. Antimicrob Agents Chemother. 1992;36:2046-8.

58. Lister PD, Wolter DJ, Hanson ND. Antibacterial-resistant Pseudomonas aeruginosa: clinical impact and complex regulation of chromosomally encoded resistance mechanisms. Clin Microbiol Rev. 2009;22:582-610.

59. Huber JL, Young K, Painter RE, Rosen H, Silver LL. Inhibition of IMP-1 Metallo- $\beta$-lactamase in Clinical Isolates by Two Succinic Acid Derivatives. Toronto: In 40th Interscience Conference on Antimicrobial Agents and Chemotherapy; 2000.

60. Winkler M, Hujer A, Bethel C, Domitrovic T, Young K, Bonomo R. Imipenemcilastatin-relebactam (IMI/REL): An analysis of resistance in Pseudomonas aeruginosa (Pa) isolates. In ICAAC/ICC 2015:C-147. San Diego, CA.

61. Naas T, Dortet $L$, lorga Bl. Structural and functional aspects of class $A$ Carbapenemases. Curr Drug Targets. 2016;17:2006-28. 
62. Rodríguez-Martínez J-M, Poirel L, Nordmann P. Molecular epidemiology and mechanisms of Carbapenem resistance in Pseudomonas aeruginosa. Antimicrob Agents Chemother. 2009;53:4783-8.

63. Ehmann DE, Jahic H, Ross PL, Gu RF, Hu J, Kern G, et al. Avibactam is a covalent, reversible, non-beta-lactam beta-lactamase inhibitor. Proc Natl Acad Sci U S A. 2012;109:11663-8.

64. Biedenbach DJ, Kazmierczak K, Bouchillon SK, Sahm DF, Bradford PA. In vitro activity of aztreonam-avibactam against a global collection of gramnegative pathogens from 2012 and 2013. Antimicrob Agents Chemother. 2015;59:4239-48.

65. Huband MD, Castanheira M, Flamm RK, Farrell DJ, Jones RN, Sader HS. In vitro activity of ceftazidime-avibactam against contemporary Pseudomonas aeruginosa isolates from U.S. medical centers by census region, 2014. Antimicrob Agents Chemother. 2016;60:2537-41.

66. Walkty A, DeCorby M, Lagace-Wiens PR, Karlowsky JA, Hoban DJ, Zhanel GG. In vitro activity of ceftazidime combined with NXL104 versus Pseudomonas aeruginosa isolates obtained from patients in Canadian hospitals (CANWARD 2009 study). Antimicrob Agents Chemother. 2011;55:2992-4.

67. Nguyen MH, Hao B, Cheng S, Shields R, Haidar G, Clancy C. Imipenemrelebactam, ceftolozane-tazobactam and ceftazidime-avibactam against carbapenem-resistant Pseudomonas aeruginosa: surveying clinical isolates for molecular markers that correlate with minimum inhibitory concentrations. Vienna: In 27th European Congress of Clinical Microbiology and Infectious Diseases; 2017.

68. Buehrle DJ, Shields RK, Chen L, Hao B, Press EG, Alkrouk A, et al. Evaluation of the in vitro activity of ceftazidime-avibactam and ceftolozane-tazobactam against meropenem-resistant Pseudomonas aeruginosa isolates. Antimicrob Agents Chemother. 2016;60:3227-31.

69. Goodlet K, Nicolau DP, Nailor MD. Ceftolozane/tazobactam and ceftazidime/avibactam for the treatment of complicated intra-abdominal infections. Ther Clin Risk Manag. 2016;12:1811-26.

70. Lapuebla A, Abdallah M, Olafisoye O, Cortes C, Urban C, Quale J, et al. Activity of Meropenem combined with RPX7009, a novel beta-lactamase inhibitor, against gram-negative clinical isolates in new York City. Antimicrob Agents Chemother. 2015;59:4856-60.

71. Lucasti C, Vasile L, Sandesc D, Venskutonis D, McLeroth P, Lala M, et al. Phase 2, dose-ranging study of relebactam with imipenem/cilastatin in subjects with complicated intra-abdominal infection. Antimicrob Agents Chemother. 2016;60:6234-43.

72. Sims M, Mariyanovski V, McLeroth P, Akers W, Lee YC, Brown ML, et al. Prospective, randomized, double-blind, phase 2 dose-ranging study comparing efficacy and safety of imipenem/cilastatin plus relebactam with imipenem/cilastatin alone in patients with complicated urinary tract infections. J Antimicrob Chemother. 2017;72:2616-26.

73. Motsch J, de Oliveria C, Stus V, Köksal I, Lyulko O, Boucher HW, et al. RESTORE-IMI 1: A multicenter, randomized, double-blind, comparatorcontrolled trial comparing the efficacy and safety of imipenem/relebactam versus colistin plus imipenem in patients with imipenem-non-susceptible bacterial infections. Madrid: European Congress of Clinical Microbiology \& Infectious Diseases; 2018.

74. Zhang R, Barbieri CM, Garcia-Calvo M, Myers RW, McLaren D, Kavana M. Moderate to high throughput in vitro binding kinetics for drug discovery. Front Biosci (Schol Ed). 2016;8:278-97.

75. Zhang R, Windsor WT. In vitro kinetic profiling of hepatitis C virus NS3 protease inhibitors by progress curve analysis. Methods Mol Biol. 2013;1030:59-79.

76. Zhang R, Wong K. High performance enzyme kinetics of turnover, activation and inhibition for translational drug discovery. Expert Opin Drug Discov. 2017;12:17-37.

77. Young K, Raghoobar S, Hairston N, Painter R, Racine F, Dorso K, et al. In vitro activity of the class $A$ and $C \beta$-lactamase inhibitor MK-7655. Boston: Presented at: Interscience Conference On Antimicrobial Agents And Chemotherapy 50th Annual Conference (ICAAC). 2010.

78. Young K, Hackel M, Lascols C, Bouchillon S, Badal R, Ocampo A, et al. Response to imipenem plus MK-7655, a novel beta-lactamase inhibitor, among 212 recent clinical isolates of $\mathrm{P}$. aeruginosa. Poster presented at: infectious disease Society of America (IDWeek). San Diego; 2012.

79. Hoban DJ, Lascols C, Nicolle LE, Badal R, Bouchillon S, Hackel M, et al. Antimicrobial susceptibility of Enterobacteriaceae, including molecular characterization of extended-spectrum beta-lactamase-producing species, in urinary tract isolates from hospitalized patients in North America and
Europe: results from the SMART study 2009-2010. Diagn Microbiol Infect Dis. 2012;74:62-7.

80. Kazmierczak KM, Lob SH, Hoban DJ, Hackel MA, Badal RE, Bouchillon SK. Characterization of extended-spectrum beta-lactamases and antimicrobial resistance of Klebsiella pneumoniae in intra-abdominal infection isolates in Latin America, 2008-2012. Results of the study for monitoring antimicrobial resistance trends. Diagn Microbiol Infect Dis. 2015;82:209-14.

81. Karlowsky JA, Lob SH, Kazmierczak KM, Badal RE, Young K, Motyl MR, et al. In vitro activity of imipenem against carbapenemase-positive enterobacteriaceae isolates collected by the SMART global surveillance program from 2008 to 2014. J Clin Microbiol. 2017;55:1638-49.

82. Cho HH, Kwon GC, Kim S, Koo SH. Distribution of Pseudomonas-derived cephalosporinase and metallo-beta-lactamases in carbapenem-resistant Pseudomonas aeruginosa isolates from Korea. J Microbiol Biotechnol. 2015;25:1154-62

83. Sievers F, Wilm A, Dineen D, Gibson TJ, Karplus K, Li W, et al. Fast, scalable generation of high-quality protein multiple sequence alignments using Clustal omega. Mol Syst Biol. 2011;7:539.

84. Huson DH, Scornavacca C. Dendroscope 3: an interactive tool for rooted phylogenetic trees and networks. Syst Biol. 2012;61:1061-7.

85. Robertson GT, Doyle TB, Du Q, Duncan L, Mdluli KE, Lynch AS. A novel indole compound that inhibits Pseudomonas aeruginosa growth by targeting MreB is a substrate for MexAB-OprM. J Bacteriol. 2007;189:6870-81.

86. Singh SB, Dayananth P, Balibar CJ, Garlisi CG, Lu J, Kishii R, et al. Kibdelomycin is a bactericidal broad-spectrum aerobic antibacterial agent. Antimicrob Agents Chemother. 2015;59:3474-81.

87. Sobel ML, Neshat S, Poole K. Mutations in PA2491 (mexS) promote MexTdependent mexEF-oprN expression and multidrug resistance in a clinical strain of Pseudomonas aeruginosa. J Bacteriol. 2005;187:1246-53.

88. Young K. In vitro antibacterial resistance selection and quantitation. Curr Protoc Pharmacol. 2006;13:13A.6.

89. Balibar CJ, Grabowicz M. Mutant alleles of IptD increase the permeability of Pseudomonas aeruginosa and define determinants of intrinsic resistance to antibiotics. Antimicrob Agents Chemother. 2016:60:845-54

90. Clinical and Laboratory Standards Institute: M07-A10. Methods for dilution antimicrobial susceptibility tests for bacteria that grow aerobically; Approved standard. Wayne: CLSI; 2015.

91. Clinical and Laboratory Standards Institute: M100-S27. Performance standards for antimicrobial susceptibility testing. 27th ed. Wayne: CLSI; 2017.

\section{Publisher's Note}

Springer Nature remains neutral with regard to jurisdictional claims in published maps and institutional affiliations.

Ready to submit your research? Choose BMC and benefit from:

- fast, convenient online submission

- thorough peer review by experienced researchers in your field

- rapid publication on acceptance

- support for research data, including large and complex data types

- gold Open Access which fosters wider collaboration and increased citations

- maximum visibility for your research: over $100 \mathrm{M}$ website views per year

At $\mathrm{BMC}$, research is always in progress.

Learn more biomedcentral.com/submissions 